\section{Con $\rightarrow$ Text: Text as Context Reading and Writing as a Pedagogical Tool Exploring Place}

\section{Julia A. Kirton}

New Mexico State University, Doña Ana Community College

\section{Clark C. Myers}

New Mexico State University, Doña Ana Community College

\section{Lamaia Vaughn}

New Mexico State University, Doña Ana Community College

Dr. Olanrewaju B. Obisesan

Dept. of Veteran Aff airs
Lack of analysis and articulation leads to weak architectural design. Every design student needs a curriculum program guided by a step-by-step progression that builds their respect for analysis, design methodology, rigor and selfconfidence. In this studio, "reading and writing to think" are the tools of exploration, employed as a pedagogical strategy where students build a strong design connection between literature and context and vice versa. This process allows students to explore themselves and their inner thoughts resulting in the unexpected, with the results of this study measured by compiling data gathered through surveillance of instructional events, instructor discussions, and assessments of content knowledge assessment; with the objective to show that "reading and writing to think" is crucial for the success of the first-year architecture student.

Text as Context -This idea of "text as context," as vocabulary becoming form cohabitating with an environment, was applied as a foundation to create new curriculum for ARCT 154 Introduction to Architectural Design, the second design studio in a series of four design studios. When starting a new design project, the architecture student needs to posit the question, "What is the meaning of the word context?" Etymology states: $($ con $=$ together $)+($ texere $=$ weave $)$. Students need to understand that the site "is" an integral part of the "context." Students need to "enter" into the context (the architectural fabric) of text. This is similar to the idea of a site $v$ isit $w$ ith $t$ angible qualities of sight, sound, touch, $t$ aste and smell. They must be trained to be highly sensitive to either acknowledge these tangible qualities or dismiss them. The decision is theirs. $T$ hey $\mathrm{m}$ ust b e able to c learly e xplain to an audience "why." "Reading, writing to think and interactive modelling" addresses this concern. Using structured design exercises, students learn to be more patient with the process, developing self-confidence and developmental tools that enrich their appreciation for intricacy and rigor in their projects as the final design is ultimately revealed.

This paper demonstrates how structured reading, writing, and an interactive modeling experience during the design process, go hand-in-hand with building self-confidence in students. "Reading and writing to think" provides them with specific developmental tools to be attentive designers. It enhances the learning experience, creating an individual who will learn to never take context for granted. The sequence of projects completed by the class during the entire semester attests to the power of context, pedagogy, and their application to the design process. (Abstract)

Keywords- context, pedagogy, assessment, critical thinking.

\section{INTRODUCTION}

Upon the completion of the Spring 2017 Design Studio II Class, on the surface the students had produced good designs. However, there were concerns. The problem - students lacked the oral and written skills required which initiated the pursuit of a different approach for the subsequent offering of the class in the Spring of 2018. So how do you analyze a built form? Past pedagogical successes in other classes with the application of the "Flipped Classroom" a pproach ${ }^{1}$ and in-class w riting reflection techniques led to the belief, "a hunch" that the assessment techniques of 
reading and writing could be the solution to student design concerns. In order to better engage the beginning design student's critical thinking, the study of a precedent, i.e. literary works as architectural context, coupled with writing and interactive modelling would lead to the evolution of more rigorous, sustainable design thinking, fueled by self-confidence and sound developmental tools in the beginning design student.

Studies have shown that countries with a high level of literacy typically have a higher GDP. Consider the NY Times article "Reading Writing and Thinking"- According to the author Geoffrey Nunberg (1981) "Today, faith in the powers of reading and writing is virtually worldwide. Literacy rates are taken to be the surest index of development (which is why many governments overstate them). Some people, in fact, have gone so far as to suggest that there is a basic human right to literacy, as there is to food, shelter and medical care."2 It would follow that if one desires a high level of pedagogical success within their local classroom population, they would need to invest in the preparation of assignments and assessment techniques that include enhanced reading and writing techniques to heighten student's critical thinking skills. This is helpful to the beginning design student.

In this case, reading is the foundational tool that supports the connection to the familiar; that being literature. When students have completed secondary education, more than likely they have completed courses in English Literature. English Literature focusses on varying writing mechanisms which are explored to understand the entire work as a whole. The introduction was structured around interesting fictional writings which helped engage the students. The analysis of the literature"Einstein's Dreams" 3 by Alan Lightman, was coupled with architectural diagramming. This first step in the design process helped the beginning design student transition from past familiar education experiences, to their present unknown of what architectural design could be.

During each project, students referenced the glossary of vocabulary and descriptions, listed in the course textbook "Language of Space and Form" [4], to support their findings throughout the semester. This emphasized the connection of text or vocabulary to the literature and connecting specific vocabulary to inherent geometries illustrated in the student diagramming. Each week, students presented their findings supported by their written summaries, helping to build self-confidence and improve their verbal presentation skills. Over the weeks, findings showed that their explanations began to illustrate their understanding of the subject matter. This should be an instructor's desired goal; to hear the confidence, understanding and explanation from their students during the design learning process.

\section{FOUNDATION \& METHODS}

\section{Instructor Desired Student Goals}

This Design Studio, the second of four design studios, focuses

on the theory of design. In this program, there are four Design Studios of which this studio is number two. This class provided the beginning design student with time to hone their skills of analysis, design methodology, rigor and most importantly, their self-confi-dence. A s design instructors, it is imperative that we meet with our peers and faculty to review new curriculum strategies before initiating the process to receive feedback. This process was undertaken. A framework was created around reading and writ-ing assignments, while improving methods of design analysis and refined model building techniques. Throughout this process, it was known that the success of any beginning design students hinges on repetition over time. "Repetition" was a major proponent of the curriculum. Grading Rubrics were revised. In order for students to meet expectations and produce quality work it was imperative that the existing grading rubrics be replaced with more detailed criteria as referenced in the Journal of Effective Teaching, Vol. 8, No. 1, 2008, 21-325. The design categories possible grading scores varied from absent / emerging, developing or implemented / integrated. Students $w$ ere trained to $c$ onsider this rubric during their design process.

The Power of Group Work

When considering pedagogy and curriculum development, successful group work assignments are a great compliment to the arsenal. Group work at the beginning of the semester addresses student accountability and can aid in unexpected student benefits and success. Let us be honest. The introduction of a new project can initiate panic in the beginning design student. Groups work aided students in studying literature ("Einstein's Dreams") in con-junction with exploring the 4th Dimension, various worlds or virtual realities. The students were provided with project tips and hints and constantly encouraged to acknowledge the support of their colleagues. For Project 1, the class was divided into two groups to initiate the investigative process, each having a team leader for the first four weeks of the semester. They were given autonomy to meet when and where they decided as we knew this present gen-eration, the "millennial student" prefers options to allow for individ-ual input. The expectation was that each student would complete their individual assignments by the next class deadline.

The assigned readings were reviewed as a group allowing stu-dents to share their own understandings of the literature with each other. They learned from each other, clarifying theirconfusion and gaining confidence from each other as they forged ahead. Students were held accountable for reading the text. They each had to sub-mit written summaries, mapped to corresponding architectural dia-grams. As a result, the class focused on student learning outcomes of architectural design - critical thinking skills and investigative skills. The translation of text by students to verbal and written for-mat, to geometrical forms improved students' respect for reading, when they saw the positive results in the work from themselves and the class as a whole. 
Supplemental Projects - Workmanship, Craftmanship and Material Support Work

"Scaffolding" projects or organizing projects from less challeng-ing to more challenging improved student success. Therefore, while Project 1 and Project 2 were on going, students were simul-taneously preparing Model Building Techniques 1 (MBT1) and Model Building Techniques 2 (MBT2). Prior Architecture Program Advisory Committee observations suggested the program focus on improving workmanship and craftmanship skills. Students were instructed to use specific types of model building materials. They learned about the structural implications in maintaining specific shapes and forms; MBT 1: Durër Letter constructed with chip board; MBT 2: Casting Concrete Forms made with Rockite or similar material. This scaffolding of assignments later increased the level of student craftmanship skills for the final project mod-els of Project 3 and Project 4. Student work was completed at a higher quality finish. These projects also aided in building student self-confidence. (See

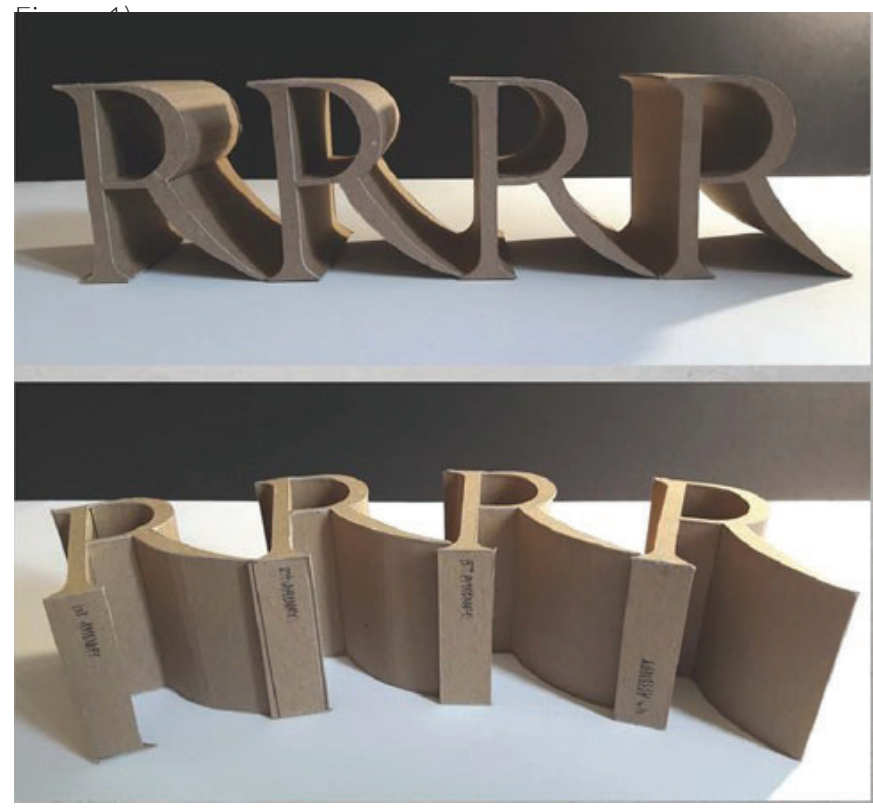

Figure 1. Student Cynthia Rivera, written summary - " The objective given to the students was to sketch and attempt to build four Durer letters out of chipboard over the course of four weeks. We were to produce a 4"x 4"x 4" craft with tech-niques that we have used in previous classes. PDF files were given to use of a book giving the guidelines of producing the sketches for the letter. We were to also choose the first letter of our first or last name. I chose the first letter of my last name which is Rivera. I had also tested the first letter of my first name, Cynthia, and c hose t he easiest letter to produce because of $\mathrm{t}$ he straight lines."

\section{THE DESIGN THEORY PROJECTS}

Initiating Investigation - Text, Diagram, Text

"Project 1 Einstein's Dreams Diagramming" (The Context).

Application: Literature + Diagramming = Analysis + Discussion
Initiating the step by step process was critical. Students read the book in approximately one month. Each week, a series of chapters were read. Students would select a preferred chapter to research further. In order to carefully assess student learning outcomes and at the same time increase critical thinking, students were instruct-ed to complete a writing reflection assessment technique similar to "3-2-1" [6]. They selected "3" specific portions of the chapter and connected each portion to a diagram which included a written explanation of "why". Students then recorded at least "2" connections to vocabulary with written explanations. Lastly students had to indicate and explain " 1 " distinct connection to spacetime, 4th dimension. Each week, the class would have interim presentation pinups and critiques.

"Language of Space and Form" (Vocabulary). Application: Analysis + Discussion + vocabulary = Form Inquiry / Exploration.

Further assessment was initiated with another teaching assessment technique called "Pair and Share" [7], to encourage students to learn from that partner for that class session and share their partners work with the class. This generated opportunities for design discussions and moments of self-discovery. As students surveyed the work, they were amazed at how similar portions of text were perceived diagrammatically different or had geometric similarities. Each week, students proceeded with this process until the book was completed. All students had a panel of nine compel-ling diagrams, each mapping to specific words or vocabulary and explanations of their applications. This reading and writing to think process generated a patch work that represented three of the four chapters. These exercises compelled students to move forward to Project 2. See TABLE 1 for reading and writing strategies below.

\begin{tabular}{|c|c|c|c|c|}
\hline \multirow[b]{2}{*}{ Projects } & \multirow[b]{2}{*}{ Duration } & \multicolumn{3}{|c|}{ Reading \& Writing Techniques } \\
\hline & & Reading Activity & $\begin{array}{l}\text { Writing } \\
\text { Activity }\end{array}$ & $\begin{array}{c}\text { Design } \\
\text { Analysis }\end{array}$ \\
\hline 1 & 4 wks & Literature & $\begin{array}{l}\text { Writing Re- } \\
\text { flection Peer } \\
\text { review }\end{array}$ & $\begin{array}{l}\text { Diagram- } \\
\text { ming } \\
\text { MBT } 1\end{array}$ \\
\hline $2 \mathrm{~A}$ & 2.5 wks & $\begin{array}{l}\text { Refence Literature } \\
\text { Reference text } \\
\text { vocad }\end{array}$ & $\begin{array}{l}\text { Writing } \\
\text { Reflection }\end{array}$ & $\begin{array}{l}\text { 2D studies } \\
\text { MBT } 2\end{array}$ \\
\hline 2B midterm & $2.5 \mathrm{wks}$ & $\begin{array}{l}\text { Refence Literature } \\
\text { Reference text } \\
\text { vocad }\end{array}$ & $\begin{array}{l}\text { Writing } \\
\text { Reflection } \\
\text { Peer review }\end{array}$ & 2D studies \\
\hline 3 & 2 wks & $\begin{array}{l}\text { Refence Literature } \\
\text { Reference text } \\
\text { vocad }\end{array}$ & $\begin{array}{l}\text { Narrative } \\
\text { Draft } 1\end{array}$ & 3D Studies \\
\hline $4 \mathrm{~A}$ & 2 wks & $\begin{array}{l}\text { Refence Literature } \\
\text { Reference text } \\
\text { vocad }\end{array}$ & $\begin{array}{l}\text { Narrative } \\
\text { Draft } 2\end{array}$ & $\begin{array}{c}\text { Context Site } \\
\text { Studies }\end{array}$ \\
\hline 4B & 3 wks & $\begin{array}{l}\text { Refence Literature } \\
\text { Reference text } \\
\text { vocad }\end{array}$ & $\begin{array}{l}\text { Narrative } \\
\text { Final Peer } \\
\text { review }\end{array}$ & $\begin{array}{l}\text { Final Design } \\
\text { Solution }\end{array}$ \\
\hline
\end{tabular}


After reading the literature, Student Cynthia Rivera chose her week 2 diagrams for further study. This led to her Project 2 analysis and supporting vocabulary: 1) Path, 2) Experience, 3) Network, 4) Palimpsest, 5) Fabric, 6 Type, 7) Iterate, 8) Filter, 9) Subtractive. (See Figure 2)

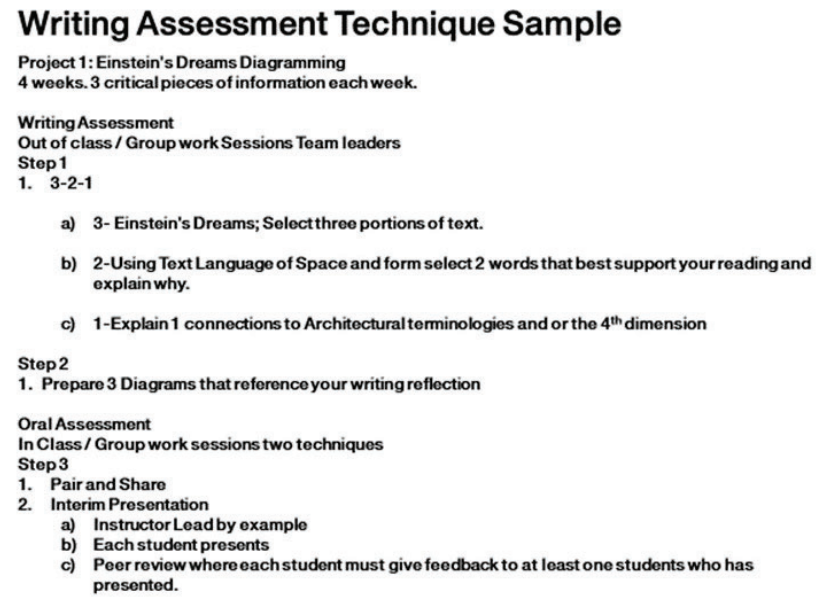

Figure 2. Writing Assessment Techniques show a sample of the possible questions students answered and submitted weekly throughout the semester.

In this sample work the student explained the vocabulary selec-tion of the word, Palimpsest - "Built up layers that reveal the state or condition of something through time. Refers to anything that displays its origins or history." In this chapter of June 9, 1905, everyone is immortal. So, in turn, everybody's ancestors still live and there are endless amounts of relatives. Every single relative has also lived a thousand lives and have done different careers. With each new person, there is another layer added to the fam-ily lines. The lines vary in weight because each line is a different generation that layer on top of each other" (See Figure 3). Her work is illustrated throughout the paper.

\section{Analysis - Collaging Reference Text}

"Project 2A: Overall Relief, Charcoal, Pastel"- required students to select 1 of the 4 weeks of diagrams for further study. Students needed to further reinforce their understanding of architectural analysis. They were introduced to various techniques, reliefs (texture exploration), charcoal, (tonal exploration), and pastel (color theory exploration), each producing 93 " $\times 3$ " tiles. For this project the reading, writing, thinking assessment assignments involved students selecting supporting vocabulary and preparing written explanations of their applications to the analysis.

Relief models are a perfect tool for moving in a "slow motion like action" from the second dimension to the third dimension. It supported the evolution of time. Along the way having students analyze form referencing vocabulary such as overlap, stacking, intersecting, allowed them to see the interstitial spaces that can be created as a result.
The charcoal study when applied in design is typically utilized to highlight shade and shadow or figure ground. Students were asked to apply a light source. They had to prepare written state-ments explaining specific angle selections and how they related to specific vocabularies. This allowed students to explore shapes and forms and how they can affect one's interaction with threedi-mensional space.

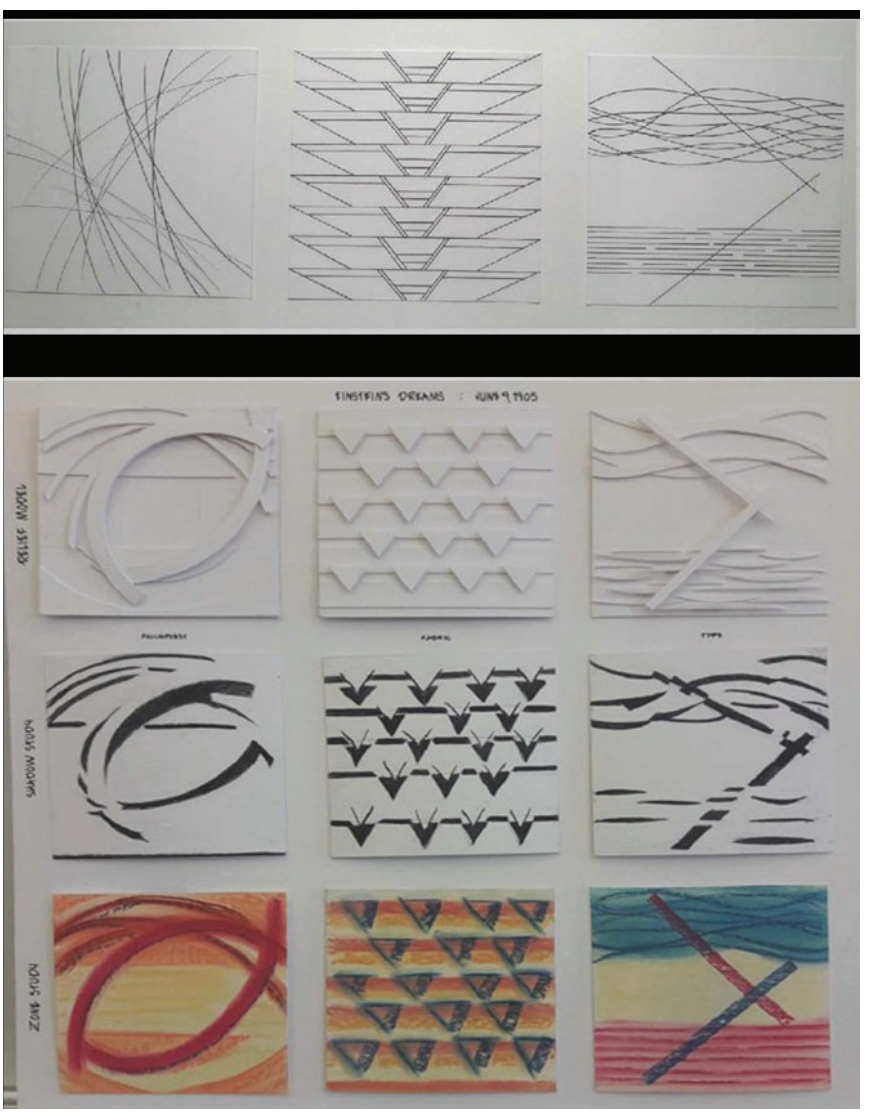

Figure 3. Student Cynthia Rivera, Sample Work, Week 2 Studies diagraming literature context with supporting text. Vocabulary illustrated, left to right: palimpsest, fabric, type. Cynthia Rivera Sample work - Project $2 \mathrm{~A}$ Final. Written summary, "The overall objective with these three-dimensional relief models is to pick one of the days we chose in the previous diagrams. We needed to layer mat-board together to a chieve height and dimension. I c hose the day $9 \mathrm{~J}$ une 1905. I felt I c onnected m ore with these diagrams b ecause, a s the s tory g oes, $t$ here a re two types of people, the Nows and Laters. Both these types of people are also immortal but they always need to look to their living ancestors for advice. This will create a layering effect which was what I was looking for. We also needed to consider a grid system as an underlying definition of time itself. Time is very important with these and future diagrams because it gives us a look into the fourth dimension."

The pastel study assisted students in revealing zones using the organizational tenants applied in architecture such as cluster, axis, gridetc.; c oncepts $t$ aught in $p$ revious lectures of ARCT 101 Introduction to Architecture. There was also a reference to similar 
topics mentioned in the current textbook "Language of Space and Form". This aided in reinforcing the Architecture Program course alignment and the importance of building on what students had already taught. The Project 2A writing assignments, placed empha-sis on the literature supported by vocabulary building on the knowledge students had gained in Project 1. Workmanship and craftsmanship was upheld with each student following the same presentation board layout. (See Figure 3).

"Project 2B Midterm: Lens, Etching \& Construct Armature", explored the application of text that supported Zone, Organization, Spatial Connection. Critical thinking was again engaged as stu-dents were expected to prepare short architectural narratives enhanced by the specific words selected from the glossary of words described in the textbook.

Transparencies and spacetime 3D vs 4D Design - The study of architecture has been revealed time and time again in the overlay-ing of form over form. Sketch tissue or tracing paper were applied - but the final presentation tool of transparency was enhanced with the advent of acrylic plastic. It is an excellent material for overlaying geometries to reveal $u$ nexpected intersections and gen-erate $n$ ew a rchitectural forms.

The class pin-up was complimented with a mid-term portfo-lio. The portfolio included both the completed project work, and edited writing assignments. Prior to the midterm submission, the instructor met with each student providing formative assessment and feedback. This ensured students reviewed their content in a timely fashion rather than rushing to complete the portfolio at the end of the semester. Qualitatively, students felt a sense of owner-ship and accomplishment. Prior to the verbal presentations, stu-dents were reminded to strengthen their theoretical arguments referencing their chosen vocabulary. They were gaining the con-fidence needed to be successful in the design studio. Reading and writing to think evidently made a difference in the student presen-tations. (See Figure 4).

\section{The Power of Analysis Modelling 3D - 4D Design}

"Project 3: 4D Construct" - "Einstein's Dreams" - The 3D Construct now transformed portions of the transparencies into three-dimensional forms with implications of the fourth dimension and time space. In essence, it generated "an object of context". For this writing assignment students prepared an architectural narra-tive. The curriculum needed to reinforce the literature and con-nection to context. Students were instructed to; State the name of the book being studied; State the chapter being studied; State the three quotes from the literature that you have been studying. List the selected vocabulary and explain the reasoning behind each design decision and model material application.

At this point, the application of the supplemental projects, Model Building Techniques 1 and 2 come into play. Students were instructed to apply visual and textural qualities to craft the study model. Students prepared final orthographic annotated study drawings, cross referencing supporting literature and vocabulary. This ensured that the presentation boards supported the
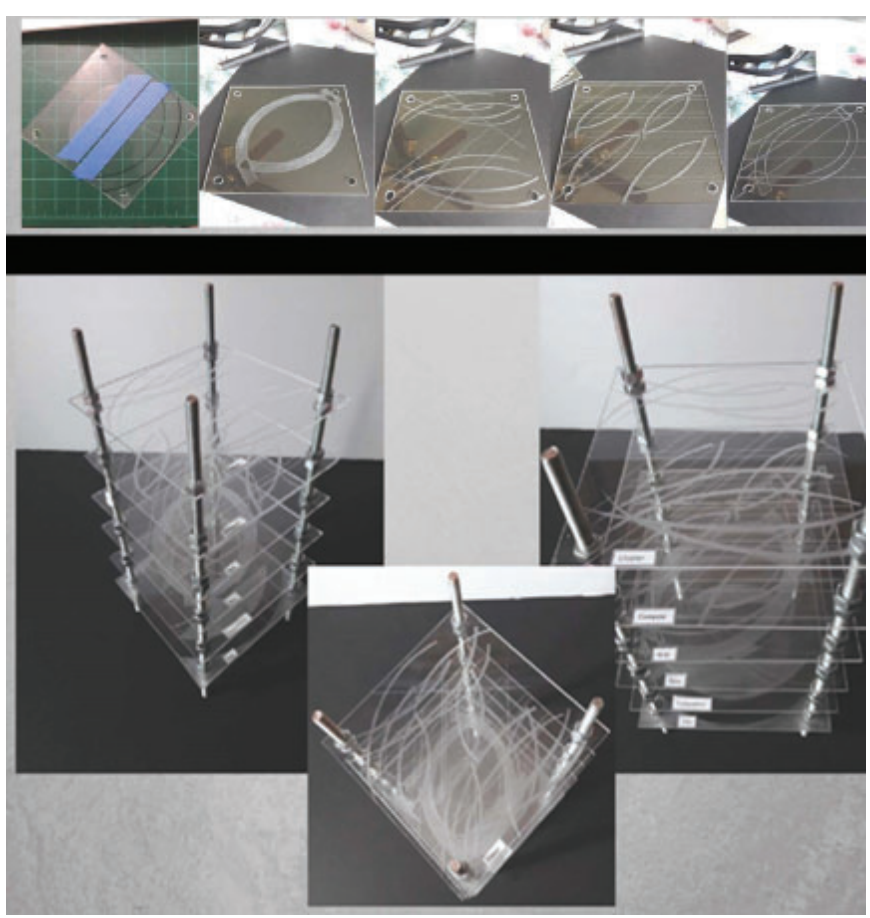

Figure 4. Acrylic transparencies prior to assembly. The study of organizational cues, new shapes generated from the intersections was paramount to the dis-covery of f orm. S tudent selected $v$ ocabulary f rom text " Language of S pace a nd Form" and justified their application e.g. 1) Edge: An outermost limit; an ending. I wanted this p lexiglass to b e the o utermost e nding of the stack. It is the beginning and t he e nd to a II of $t$ he $d$ iagrams. 2 ) Zone: A $\mathrm{n}$ a rea $\mathrm{d}$ istinguished b y a p articular characteristic. 3) Cluster: A grouping of similar things, elements bound into a group that is distinct of other groups. I wanted to keep the curves clustered together to show the different types on either end of the diagram. The two intersecting curves leave empty zones at their intersection.

4D theoretical argument and written narrative. Prior to the Final Presentation, to encourage further accountability, each student received formative instructor feedback to review narrative com-pleteness during desk critiques. (See Figure 5, 6).

\section{The Context as Text Taking Shape}

"Project 4A: Phase \#2 Site \& Object" - Here, students were instructed to generate the shapes or forms of the context or site of the specific world they had been studying for the semester. The site was composed by applying specific words selected from the textbook "Language of Space and Form". A written summary was prepared to support the design process and the connection to the literature of "Einstein's Dreams". Each time a student felt lost or disconnected, they were reminded to re-read their notes and writings composed throughout the semester. This helped to 
refocus the beginning design student. Their written notes were critical reminders of their personal journey and thought process over time. "Reading Writing and Thinking" were a constant sup-port to the design process. Student confidence at this point is beginning to soar.

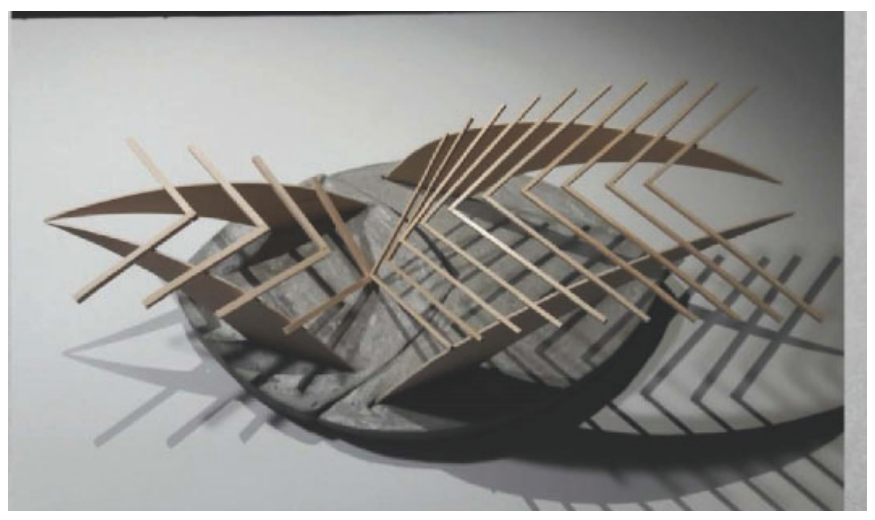

Figure 5. Student wrote, "In the world of Einstein's dreams, the day of June 9th, 1905, people are immortal. People live so long, everyone is able to speak to their ancestors to $\mathrm{g}$ ain insight o $\mathrm{n}$ a ny e ndeavors they $\mathrm{m}$ ight $\mathrm{p}$ roceed $\mathrm{w}$ ith. $\mathrm{M}$ y I enses that we were to create reflect the relief studies from previous projects. I had picked $t$ he $f$ irst relief $m$ odel as the $b$ asis of $t$ he p rimary s hapes I w ould later use in my 4-dimensional construct. I broke up the relief model into zones, which gave me t he $b$ asis of $m$ y $f$ irst three lenses. Those lenses $f$ urther helped $m$ e c onstruct the $b$ ase of $m$ y 4 -dimensional model."

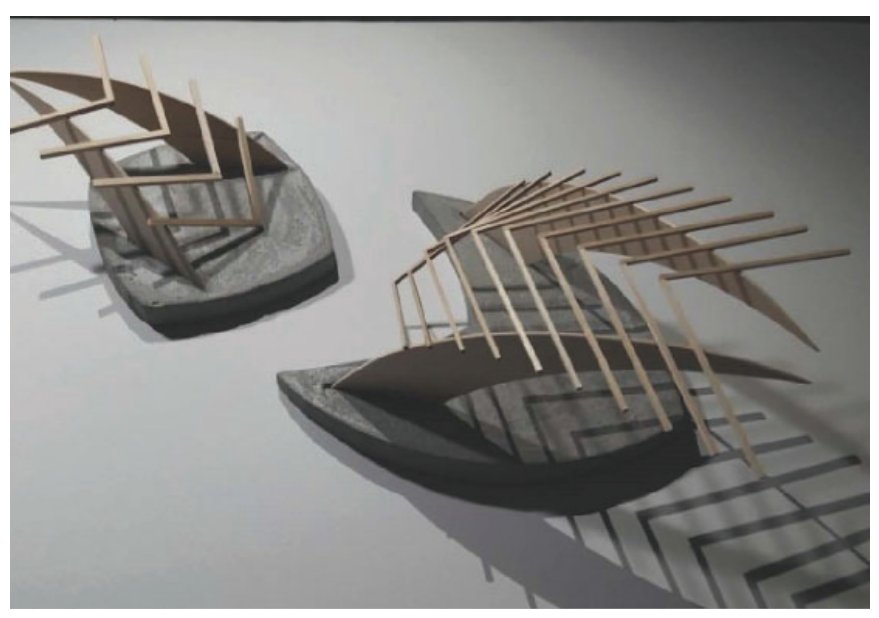

"I brought that into my model with the standing curves inlaid into the c oncrete. The taller the curve coming out of the concrete represents the people who learn as much as possible. The smaller standing curve represents those who take their life easier. In my model, I decided to keep both types of people separated by constructing different sized models to represent the different direction of both these people are moving in time. The curves rise from the foundation of the concrete to represent the direction of time itself. The concrete is the pool of endless generations of which the immortal people come from. The linear bass-wood represents the many generations of which the immortal people build upon in their legacy. Each generation is iterative as they repeat what their ancestors before them have a lready d one."

\section{Inhabiting Context - Text as the Vehicle}

"Final Project 4B: Experience "House of Relative Time".

Compound Project Site \& Object" - The exploration of place is culminating into one of many possible solutions. Students must occupy the site with the appropriate structure or structures to tell their full contextual story of time based on individual research. The application of orthographic projection; Plan, Section, and Elevation studies support course alignment. final writing assignments instruct students to prepare a narrative which consider compos-ing space, arranging forms and material exploration. "Literary con-text" as the space was heavily influenced by the exploration of the world from "Einstein's Dreams". Student's writings had to explore what a "dwelling" in this constructed world would look like through their iterative process. They had to prove their thesis. Students were asked to prepare a final architecture narrative to summa-rize the semester's work. At this point in the project, the rigourous assessment assignments of reading and writing to critically think generated a class of student work worthy of review, analysis and prolonged discussion during final critiques.

\section{CONCLUSION}

\section{Peer Review and Observations}

The challenge of teaching architecture students in a lower income, semirural community presents additional obstacles to suc-cess. Integrating traditional academic practice (reading and writ-ing), as a means to develop better architectural solutions from the beginning design student was implemented in the 2018 studio. By providing a familiar structure (reading and writing) to a challenging and indeterminant problem, the students improved both communi-cative and cognitive skills as evidenced in improved grades/success. All faculty familiar with the programs completed a survey, which noted that there was a marked improvement in the craftmanship and workmanship of the model building. Comparing students' work to that of p revious semesters, the reviewing c ritics also agreed that the work was greatly improved through the structured exercises involving cyclical reading and writing, which mimicked the tradi-tional iterative design process of the architecture studio. Through the weekly routine of repetition and rewriting assignments applied to architecture, the students were able to see their progress, build their design confidence and execute more competent work. 
Observations of student work from periodic reviews during semester

- Applications Project 1 - Diagrams - Through guided reading, writing, diagramming, the students work exhibited growth and development from their initial tentative attempts to later solutions. W ith rigorous application of this cyclical process, s tudents appeared more confident both verbally and graphically.

- Model Building Techniques 1 - Durer Letters - Encouraging craft and construction through repetition, this phase emphasized parallel growth in "making" and productive confidence.

- Project 2A - Relief, Charcoal, Pastel - Further exploration of graphic expression and emergence of potential architectur-al expression from the contextual investigations. Expanding use of architectural terminology as applied to the text references is reflected in the final presentation board (Figure 3).

- Model Building Techniques 2 - Rockite Model - Another paral-lel activity that investigated material and technique in pursuit of future architectural model.

- Project 2B - Lens Armature - Student projects exhibited applica-tion of a design narrative based on architectural terminology in the Lens Armature, an investigation of layer, transparency, and textual interpretation.

- Project 3 - Lens Armature 3D-4D Model - Continued development of the project - Reviewing the student work (See Figs. 5,6 ), I was impressed by the strong clarity and clean craft of the model. The students in general were able to defend their projects supported with both architectural terms and textual references. At this point in the semester, the students were beginning to assemble more complex solutions using earlier material explorations.

- Project 4A - Site and Object and Project 4B - House of Relative Time: Final presentations by students represented the culmination of the semester's design investigations and clearly showed the strength and clarity of concept that the reading and writing to think process had encouraged. The work was grounded in a textual site through the buildup of analysis and reflection. Like the action of writing, rewriting and editing, the design process benefited from the iterative cycle and enabled the students the confidence to explore abstract architectural solutions. (See Figs. 7, 8)

\section{Observation and Conclusions}

The application of a design process that emphasizes investiga-

tive and reflective writing in concert with graphic and constructive exploration produced a vast improvement in the design studio. The reading and writing provided students with both definition and confidence to proceed with their architectural projects. Through the semester, the student work grew stronger as they relied on their reflective writing which guided their solutions and provided intentional design clarity rather than muddled architecture. While the initial premise of using literature and writing as a basis for architecture may have begun tentatively, the students through the semester showed marked improvement and embraced the process, perhaps due to their familiarity with the practice of earlier reading and writing. The class format encouraged the students to explore the text deeply, relying on their own interpretations, to develop real architecture grounded in a theoretical foundation.

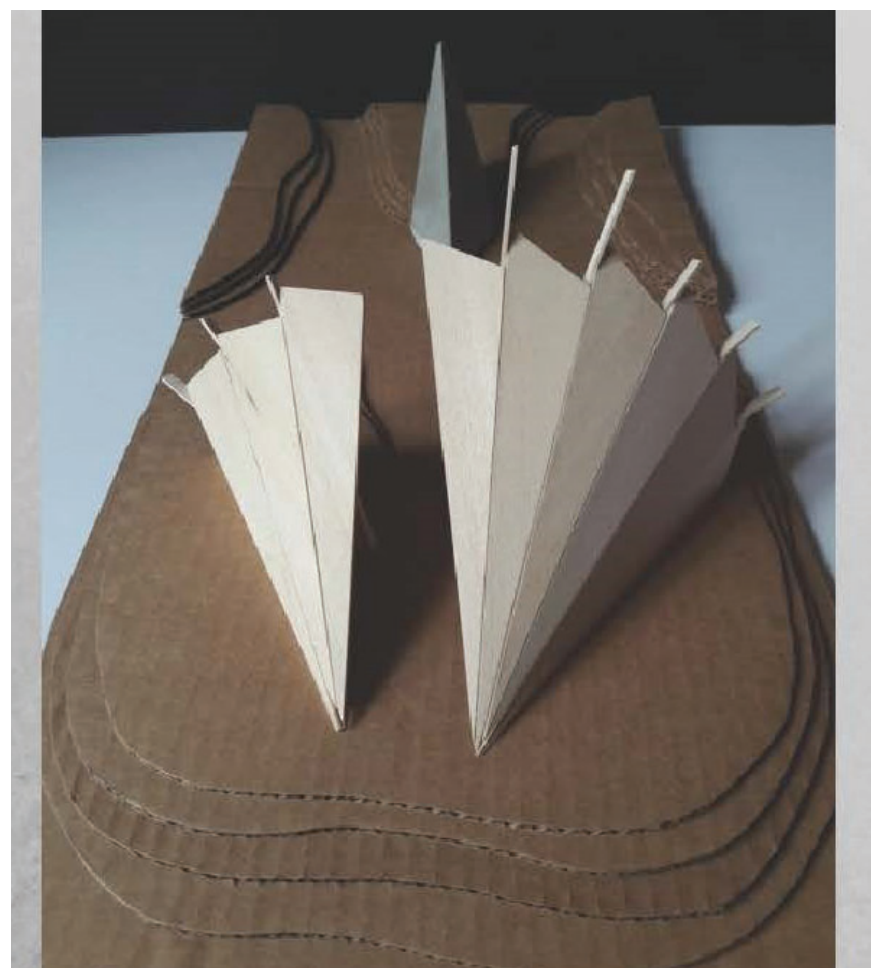

Figure 7. Sample work Student Cynthia Rivera- here we see the design studio final project and the text becoming context as the o bject inhabited the site. S tudent final vocabulary connections to text "Einstein's Dreams" as context -Portal: "A doorway, gate, or other entrance, especially a large and elaborate one." In my world, the s tructures that stand side by s ide, a re a p ortal to introduce

u s to the two types of people, the "Laters" and "Nows". The portal, located in between the structures, a cts as a v iew into the lives of p eople. Threshold: "

The p oint of e ntry or beginning." G oing t hrough t he $p$ ortal, $t$ he $t$ hreshold of t he structure is where we finally enter into the center of the structure. This is where the "Laters" and "Nows" congregate or go inside their respective structures to learn their knowl-edge. Expansion: "a thing formed by the enlargement, broadening, or develop-ment of something." The structures themselves are open so the types of people could expand o n their knowledge."

Student's $\mathrm{f}$ urther application of $\mathrm{t}$ ext - Repetition: " the a ction of repeating s omething that has already been said or written." The structure's basswood pieces represent the repetition of information being learned. Being that both types of people are immortal, they will tend to repeat any careers or ventures their ances-tors h ave a Iready d one. Layering: "a thickness of s ome $m$ aterial laid o n o r spread over a surface, stratum." The layering of the basswood shows the many grow-ing generations of Laters and Nows. Articulation: "the state of being jointed." Basswood pieces that are in the middle, join together at the middle because that direct p oint represents e ach t ype of p eople f rom their point of o rigin." 


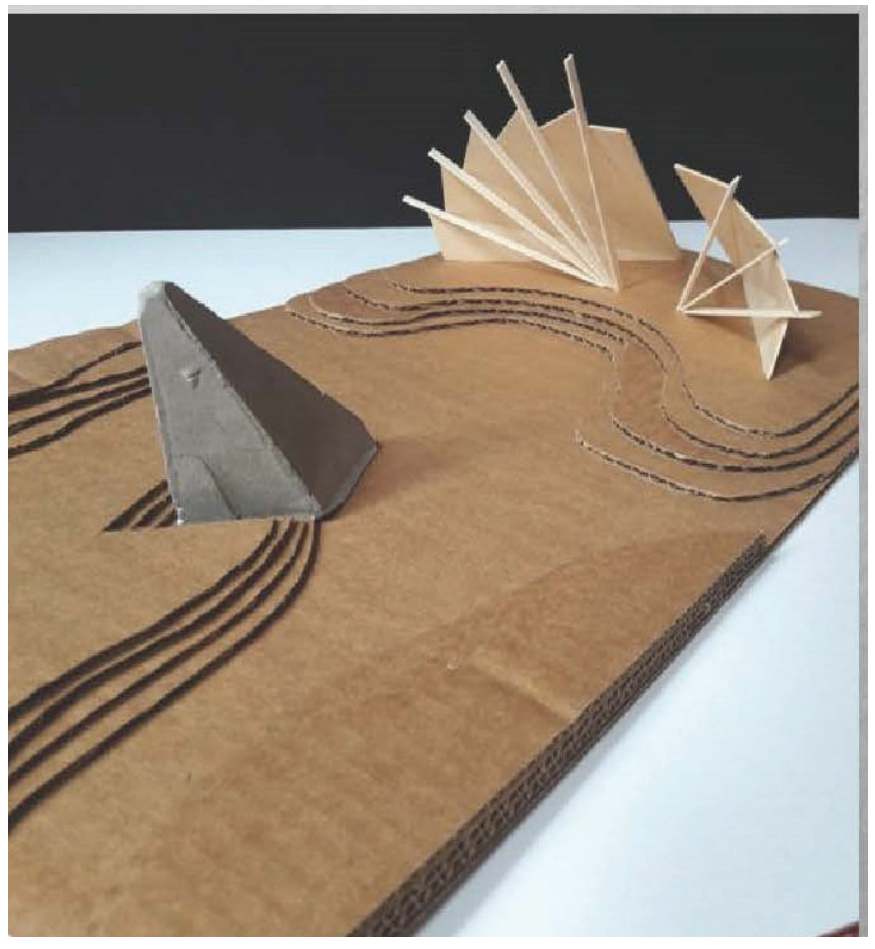

Figure 8. Student application of materials. "Basswood: I wanted the basswood to give texture because it is said that wood holds energy and information. Each line and each layer shows many generations of the Laters and Nows. The lines are an epitaph of all the people that came before the new generation. The new generations of purple are adding to those lines and give the basswood more texture. Concrete: The concrete pyramid towards the center gives meaning to the immortal people. It represents the direction of time flowing forward, but also gives weight. This weight shows how time is forever weight on their shoulders of their immortality."

\section{Reflections and Future Considerations}

Applications of these techniques $w$ ill b e $s$ tudied $f$ urther in $f$ uture design studios. In this case, it was literature focused on the subject matter of context and the 4th dimension. Other topics of inter-est such as concepts of structure or social issues are being con-sidered. Research completed through the paper "The Effects of Reading and Writing Upon Thinking and Learning" [8] studied spe-cific writing techniques of reasoning and discourse. For instance, introducing students to Reasoning Operations of writing (pp. 5), as mentioned in the paper, that will ask students to hypothesize or ask particular thesis questions can be quite revealing for a design. Or consider the topic Discourse Purposes ( $\mathrm{pp} \mathrm{7)}$ which referenced the outcomes of analysis and generation that were similar to the research criteria explored in this semester, producing successful outcomes as well.

Since this prior success, writing assignments have already been included in the first studio, Design Studio I and will be reinforced in Design Studio III and IV. This process elevated the students criti-cally thinking. Official college course student evaluation comments were also very encouraging. (See Student Eval. Exceprts)
Student A "Enjoyed this class! is very different and the professor is always encouraging us to do our best."

Student B • "I've enjoyed this semester although stressful but being in a studio class has more assignments and projects that go along with the class which is expected. I have learned a lot and have learned to look at design in a new way due to our projects over the course of this semester. Ms. Kirton has pushed our thinking and creativity to the next level and I'm thankful we have her as a teacher!!"

- Student Eval. Excerpts

When comparing a class of six students versus sixteen students, one could argue that the students were more engaged because they had more colleagues to interact with and share ideas. But in considering past small studio sizes in second year studios, the stu-dents that had the greater design success were always the ones that did more indepth design research and report writing. Though the data pool at this time may be small, there was still a noted improvement. When comparing the grades of the Spring 2017 Design Studio II versus Spring 2018 class, the overall class per-formance had improved. For the Spring 2018 class, 84\% received a grade of $\mathrm{B}$ or higher, compared to the Spring 2017 class, where 42\% received a grade of $B$ or Higher. These types of results encourage instructor curriculum development driven by "reading and writing to think" assignments that will aid the beginning design student to be a part of a more vibrant design studio culture, for a lifetime of sustainable design decisions to come.

\section{ACKNOWLEDGMENT}

I want to thank my colleagues. Professor Clark Myers AIA., thank you for your curriculum input, critique and peer review. Professor Lamaia Vaughn, thank you for your support, preparing and editing the abstract that started us on this journey to share pedagogical triumphs with those who care about student accountability, growth and success. Dr. Olanrewaju Obisesan, thank you for your editing support, tough reality checks and encouragement. To my student Cynthia Rivera; congrats to you for all your hard work. You were awesome to work with as a student. You will no doubt go on to do great things.

\section{REFERENCES}

[1] Flipped Classroom the preparation of readings ahead of class meetings.

[2] Nunberg, G. "Reading, Writing and Thinking." NY Times, December 13, 1981. Accessed March/April, 2019.

https://www.nytimes.com/1981/12/13/books/read-ingwriting-and-thinking.html.

[3] Lightman, A. and Griese, F. (2015). Einstein's Dreams. München: Droemer Taschenbuch 
[4] Eckler, J. (2012). Language of Space and Form. New York, NY: John Wiley \& S ons.

[5] Connelly, M. and Wolf, K. (2008). A Tale of Two Rubrics: Improving Teaching and Learning Across the Content Areas through Assessment. Journal of Effective Teaching, Vol. 8, No. 1, 21-32

[6] 3-2-1-Writing assesment technique - where students focus on three specifc concepts or precedent, con-sider two of their own applications of that concept and finally share an overall idea or ask for further clarify or share a concern.

[7] Pair and Share - for this assessment technique, tudents are placed in pairs to discuss specific subject matter and then asked to share their partners concepts and share their own thoughts as it pertains to their partners views.

[8] Ideals.illinois.edu. (2019). [online] Available at: https:// www.ideals.illinois.edu/bitstream/handle/2142/17778/ ctrstreadtechrepv01989i00477_opt.pdf?sequence=1 [Accessed 9 Aug. 2019]. 